\title{
A review of fully coupled atmosphere-hydrology simulations
}

\author{
NING Like ${ }^{1,2}$, ${ }^{*}$ ZHAN Chesheng ${ }^{3}$, LUO Yong ${ }^{1,2}$, WANG Yueling ${ }^{3}$, \\ LIU Liangmeizi ${ }^{3,4}$
}

1. Ministry of Education Key Laboratory for Earth System Modeling, Department of Earth System Science, Tsinghua University, Beijing 100084, China;

2. Joint Center for Global Change Studies, Beijing 100875, China;

3. Key Laboratory of Water Cycle and Related Land Surface Processes, Institute of Geographic Sciences and Natural Resources Research, CAS, Beijing 100101, China;

4. University of Chinese Academy of Sciences, Beijing 100049, China

\begin{abstract}
The terrestrial hydrological process is an essential but weak link in global/regional climate models. In this paper, the development status, research hotspots and trends in coupled atmosphere-hydrology simulations are identified through a bibliometric analysis, and the challenges and opportunities in this field are reviewed and summarized. Most climate models adopt the one-dimensional (vertical) land surface parameterization, which does not include a detailed description of basin-scale hydrological processes, particularly the effects of human activities on the underlying surfaces. To understand the interaction mechanism between hydrological processes and climate change, a large number of studies focused on the climate feedback effects of hydrological processes at different spatio-temporal scales, mainly through the coupling of hydrological and climate models. The improvement of the parameterization of hydrological process and the development of large-scale hydrological model in land surface process model lay a foundation for terrestrial hydrological-climate coupling simulation, based on which, the study of terrestrial hydrological-climate coupling is evolving from the traditional unidirectional coupling research to the two-way coupling study of "climate-hydrology" feedback. However, studies of fully coupled atmosphere-hydrology simulations (also called atmosphere-hydrology two-way coupling) are far from mature. The main challenges associated with these studies are: improving the potential mismatch in hydrological models and climate models; improving the stability of coupled systems; developing an effective scale conversion scheme; perfecting the parameterization scheme; evaluating parameter uncertainties; developing effective methodology for model parameter transplanting; and improving the applicability of models and high/super-resolution simulation. Solving these problems and improving simulation accuracy are directions for future hydro-climate coupling simulation research.
\end{abstract}

Keywords: land surface hydrology; regional climate model; fully coupled atmosphere-hydrology simulation; water cycle; research review

Received: 2018-05-18 Accepted: 2018-06-30

Foundation: National Key R\&D Program of China, No.2017YFA0603702; National Natural Science Foundation of China, No.41571019, No.41701023, No.41571028; China Postdoctoral Science Foundation, No.2017M610867

Author: Ning Like (1986-), PhD, specialized in climate change, hydrology and water resources. E-mail: ninglk@igsnrr.ac.cn

*Corresponding author: Zhan Chesheng (1975-), Professor, E-mail: zhancs@igsnrr.ac.cn 


\section{Introduction}

The terrestrial water cycle is an important process in the Earth system. As the effects of human activities on global climate change have become increasingly prominent, extreme hydrological events (such as floods and droughts with high frequency and duration) have increased. Simultaneously, the uncertainty in estimating the amount of water resources for ecological and economic water use and hydropower resources has also increased. The interactions and feedbacks between regional climate change and land surface hydrological processes have become one of the most essential issues in climate change and water resources research (Bates et al., 2008; IPCC, 2015). In addition, understanding the regional hydrological response process, which is jointly influenced by climate change and human activities, is one of the major strategic needs of China. The National Plan for Medium \& Long-term Scientific and Technological Development states that the response of large-scale hydrological cycles to global change and the impact of global change on regional water resources is a fundamental research focus in the areas of global change and regional response. Therefore, simulations of regional climatic-terrestrial hydrology in specific basins are of great scientific significance and application value. These simulations can help understand the spatial and temporal evolution of the terrestrial water cycle in the context of global climate change; assess the impacts of climate change and human activities on the security of water resources; and safeguard the sustainable development of the economy.

Compared to global climate models, regional climate models have higher resolution and accuracy. However, the scale of regional climate models is too coarse to capture the hydrological processes of specific river basins. As traditional hydrological models mostly simulate two-dimensional or three-dimensional hydrological processes based on a homogeneous, high-resolution underlying surface, the results are more accurate than those of climate models.

Due to their different focuses, hydrological and climate models have been developed independently for a long time. However, there is an urgent need to couple climate and hydrological models to investigate the interactions and feedbacks between regional climate and land surface hydrological processes.

Since the beginning of the 21 st century, the World Climate Research Program, the International Geosphere-Biosphere Program and the Global Energy and Water Cycle Experiment Program have all adopted coupled atmosphere-hydrology simulations (Liang et al., 1998). Hence, developing a large-scale water cycle simulation system that can effectively describe the spatio-temporal evolution of the water cycle and quantitatively evaluate the hydrological resources within a certain region has become an important issue in global climate change research (Guo and Liu, 1997; Yong et al., 2009).

This paper analyzes the development status, trends and hotspots in research on coupled atmosphere-hydrology simulations based on a scientific literature review. Based on a comprehensive review on the runoff scheme of land surface process model and development of large-scale water cycle model, this paper expounds on the development of atmosphere-hydrology coupling simulation from one-way coupling to two-way coupling and identifies the main problems and challenges related to the two-way coupling of atmosphere-hydrology simulation. 


\section{Bibliometric analysis of atmosphere-hydrology simulations}

\subsection{Development trends in atmosphere-hydrology simulations}

To explore the trends and development of fully coupled atmosphere-hydrology simulation, we performed a topic search that aimed to capture the maximum possible amount of relevant literature using the Web of Science Core Collection, which includes the SCI and the SSCI (Social Science Citation Index) databases. We used the terms [("climate model" OR "regional climate model" OR "land surface model" OR "land surface scheme*" OR "land surface parameterization*") AND ("hydrology" OR "hydrolog* model” OR "hydrological cycle" OR "water cycle")] as the search queries. A record was considered relevant if the terms were found in the keywords, title, or abstract of the publication. The queries resulted in 1617 records as of September 2016. Among these records, original research articles accounted for $96.4 \%$ (1558 records), and reviews accounted for 3.6\% (59 records). Other literature types (e.g., proceedings papers and notes) were omitted from this study.

Figure 1 shows the yearly distributions of papers published and the number of cited references across their publication years based on the searched literature. It also shows that the attention paid to atmosphere-hydrology has rapidly increased in academia. The earliest cited reference year visible in Figure 1 is 1986, the earliest reference publication year is 1990, and the earliest cited reference year is 1994 . The number of yearly publications increased almost 10 -fold in the past 20 years. Approximately $77 \%$ of all papers were published between 2006 and 2016, suggesting exponential growth in coupled atmosphere-hydrology research.
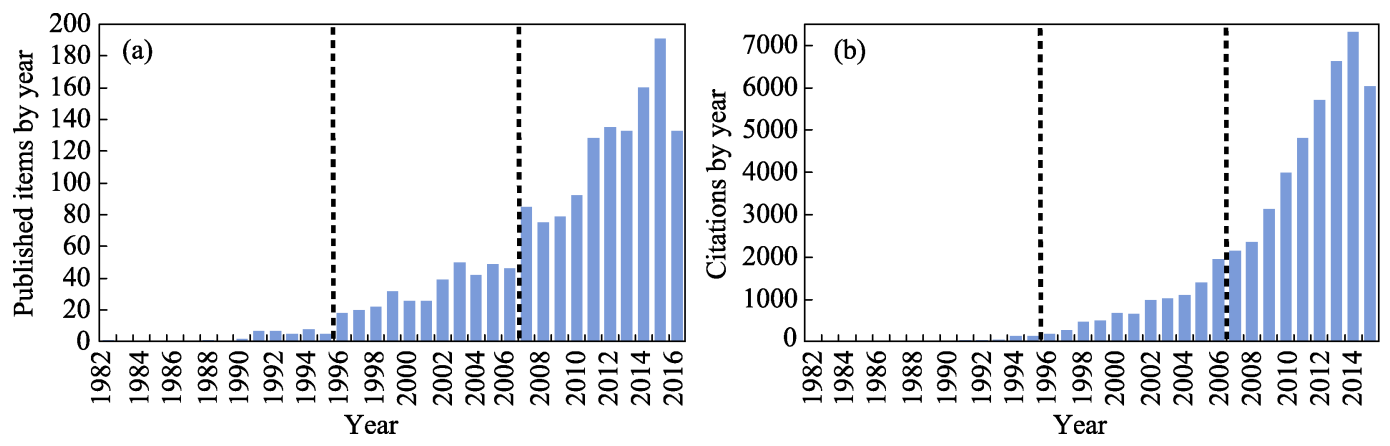

Figure 1 Published items (a) and citations (b) by year

The number of papers published per year reflects the academic input and interest in the investigation of coupled atmosphere-hydrology, and the citation frequency reflects the attention paid to the subject by academia and the public. Based on the trends in published items and citations, the development of atmosphere-hydrology research can be divided into three stages/periods as follows: (1) The embryonic stage of atmosphere-hydrology research occurred before 1996. In this stage, less than 10 papers were published each year, and the number of citations was below 150. The studies published during this period mainly focused on the parameterization of hydrological models in climate and land surface models. (2) The initial development stage of atmosphere-hydrology research occurred from 1996 to 2006. During this period, the number of papers published each year was within 50 , and the number of citations was under 2000. Studies during this period mainly focused on the spatial and temporal distributions of water resources using climate models, land surface models and 
hydrological models. (3) The diversified stage of atmosphere-hydrology research occurs after 2006. In this stage, the amount of papers published and citation frequency increased dramatically, indicating that the topic is attracting growing attention in academia and society. In addition, the coupling of climate or land surface models with hydrological models has become increasingly relevant in this stage. Meanwhile, large-scale hydrological models and global hydrological models have seen substantial development.

\subsection{Keywords of atmosphere-hydrology simulations and their distribution in major countries}

As the identifiers for retrieving scientific papers, keywords can clearly express the subjects of papers and serve as key indicators of emerging trends within a field of study. In this review, 1762 unique keywords were obtained by merging and cleaning up from 1617 articles. Figure 2 shows a keywords cloud and the distribution of the top 10 keywords in primary research countries. In the keywords cloud, the size of the keyword reflects the frequency of its occurrence. The keywords cloud shows that the interactions between climate change and the hydrological cycle were studied by employing climate model/regional climate model or land surface model cooperated with hydrological model. The keywords cloud also shows that the main technical methods in our topic were remote sensing, data assimilation, error correction, and descending scale (statistical descending scale and dynamic descending scale), while the main models were General Circulation Models (GCMs), the Soil and Water Assessment Tool (SWAT), the Weather Research and Forecasting (WRF) model, Variable Infiltration Capacity (VIC) and Community Land Model (CLM). The published research focused on the impacts of climate change and human activities (including land use) on the hydrological cycle and water resources, which can be further decomposed into runoff simulation, snowmelt/thaw runoff simulation, soil moisture change, precipitation change, evapotranspiration change, groundwater change, terrestrial-atmospheric interaction, and model uncertainty evaluated by the model intercomparison plan.

(a)

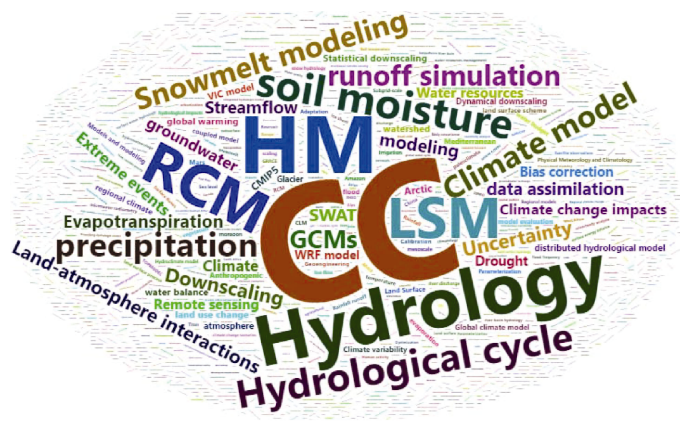

" Climate change

- Land surface model

(b) - Climate model 100

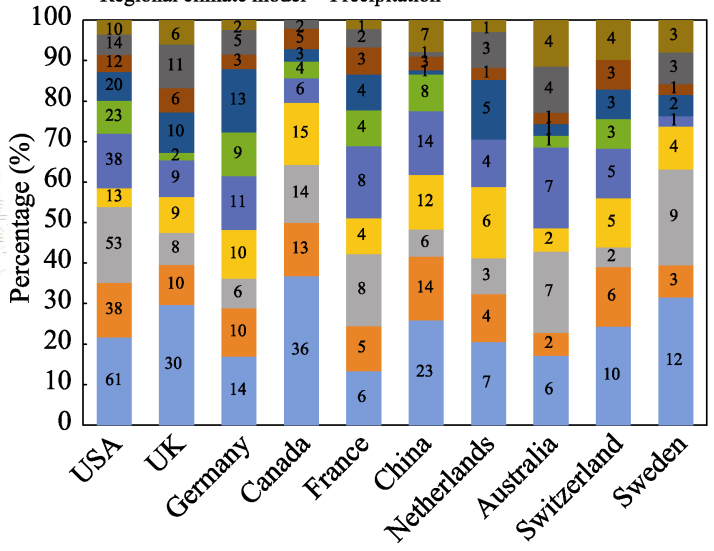

Figure 2 Keywords of published atmosphere-hydrology simulation papers (a) and their distribution in major countries (b) (CC: climate change; HM: hydrological model; LSM: land surface model) 
The top ten keywords were analyzed statistically to investigate their distributions in the primary research countries. The top 10 keywords were "climate change", "hydrological model", "hydrology", "regional climate model", "land surface model", "soil moisture", "hydrological cycle", "precipitation", "climate model", and "runoff simulation".

The numbers in Figure $2 b$ indicate the frequencies of the keywords. The length of the bar of each keyword represents the proportion of the keyword in related published articles in each country. The frequencies of the top ten keywords were higher in the USA than in other countries, especially for climate change, hydrological model, hydrology and land surface model. This indicates that soil water, hydrological cycle and climate model research is advanced in the USA. UK has more research on climate change and climate model over other countries. Meanwhile, the distribution of keywords is relatively uniform in Germany, where research related to land surface and hydrological models is highly developed. In Canada, research is predominantly focused on climate change, hydrological models, hydrological theory and regional climate models. Compared with other countries, research on climate change, hydrological model and regional climate model in China is in the former position. However, its research on climate models and the hydrological cycle is relatively weak and should be strengthened.

\section{Foundations of coupled atmosphere-hydrology simulations: Improvement of land surface models and development of large-scale hydrological models}

\subsection{Improvement of land surface models}

In atmosphere-hydrology simulations, the land surface model is the common interface between hydrological and atmospheric processes. Thus, accurate simulations of large-scale terrestrial water are vital to studies of atmospheric processes and climatic change. Since the simple bucket model was developed, the schemes of terrestrial hydrological processes in land surface models have been continually updated and revised (Manabe, 1969). The Project for Inter-comparison of Land-surface Parameterization Schemes, launched in the 1990s, has shown that third-generation land surface models that include remote sensing data and consider carbon cycling are improving the simulation of hydrological processes and could be used to simulate long-term changes in climate and terrestrial water resources. Representative models include the Noah land surface model (Livneh et al., 2010), the common land model (Dai et al., 2003), and the community land model (CLM) (Decker and Zeng, 2009; Oleson et al., 2010). Among them, CLM has a sub-grid structure, which is beneficial for the simulation of soil moisture and water heat flux. However, most land surface models adopt a one-dimensional, single-column structure to parameterize hydrological processes, which may worsen the accuracy of runoff simulations compared to using a hydrological model.

Table 1 summarizes some parameterization schemes used for runoff generation and river routing in land surface models. As shown in Table 1, the parameterization schemes of most land surface models remain imperfect, especially the lack of human activities in the parameterization schemes. Since most land surface models are designed with a one-dimensional, single-column structure, the simulated runoff process is mainly the response of the entire basin to precipitation, which fails to reflect the lateral movement of soil moisture and the interaction between surface water and sub-surface water. Furthermore, most of the simulated 
runoff is no longer involved in the related vertical water balance calculations (e.g. the recharge and evaporation of the river), which leads to some deviation when simulating land surface runoff (Sahoo et al., 2008; Ning et al., 2016; Li et al., 2017). This deviation further affects the soil moisture, thereby influencing the climate simulation (Yang et al., 2007).

Table 1 Comparison of parameterization schemes of runoff generation and river routing in land surface models

\begin{tabular}{|c|c|c|c|c|}
\hline \multirow{2}{*}{ Model } & \multicolumn{2}{|c|}{ Runoff scheme } & \multirow{2}{*}{ Routing scheme } & \multirow{2}{*}{ Human water use } \\
\hline & Surface & Subsurface & & \\
\hline BASE & Saturation excess & Gravity drainage & No & No \\
\hline BATS & Saturation excess & Gravity drainage & Basin aggregation of runoff & Chen and Xie (2010) \\
\hline BUCK & Saturation excess & Bucket drainage & No & No \\
\hline CLASS & Saturation excess & Gravity drainage & $\begin{array}{l}\text { Linear reservoir cascade \& } \\
\text { unit hydrograph }\end{array}$ & No \\
\hline IAP94 & Saturation excess & Not quite clear & No & No \\
\hline ISBA & Saturation excess & Gravity drainage & MODCOU & No \\
\hline MOSAIC & Saturation excess & Downslope drainage & No & No \\
\hline PLACE & Infiltration excess & $\begin{array}{l}\text { Lateral flow and } \\
\text { gravity drainage }\end{array}$ & No & No \\
\hline SSIB & Saturation excess & Gravity drainage & TOPMODEL & No \\
\hline UKMO & Infiltration excess & Gravity drainage & No & No \\
\hline VIC-3L & Saturation excess & $\begin{array}{l}\text { Nonlinear Arno base } \\
\text { flow curve }\end{array}$ & $\begin{array}{l}\text { Unit hydrograph \& } \\
\text { linearized St. Venant }\end{array}$ & Haddeland et al. (2006) \\
\hline MATSIRO & TOPMODEL & $\begin{array}{l}\text { Lateral flow and } \\
\text { gravity drainage }\end{array}$ & TRIP & Pokhrel et al. (2012) \\
\hline $\mathrm{LaD}$ & Saturation excess & Not quite clear & Basin aggregation of runoff & No \\
\hline JULES & Infiltration excess & Gravity drainage & No & No \\
\hline CLM & TOPMODEL & $\begin{array}{l}\text { Lateral flow and } \\
\text { gravity drainage }\end{array}$ & Linear reservoir & Zou et al. (2014) \\
\hline
\end{tabular}

Considering the importance of two-way feedbacks of atmosphere-hydrology processes, some researchers have attempted to conduct fully coupled atmosphere-hydrology simulations by inserting algorithms from hydrological models directly into land surface models to improve the hydrological process in the land surface models.

For example, Habets et al. (1999) coupled the interface-soil-biosphere-atmosphere scheme within land surface models with a large-scale hydrological model to update the surface runoff scheme. The coupled model improved the simulation of daily runoff. Seuffert et al. (2002) coupled the TOPMODEL-based land surface-atmosphere transfer scheme with a local (mesoscale) weather model. The results showed that the coupled model improved the simulation of energy flux and rainfall, although some deviations remained in the boundary layer structure. Zeng et al. (2003) replaced the hydrological process in the biosphere-atmosphere transfer scheme (BATS) by the hydrological model VXM (a combination of the VIC and Xinanjiang models) to improve the simulation of infiltration and runoff. These studies only altered an algorithm or replaced a process in the land surface model, which may result in model consistency errors and lead to the poor simulation of climatic factors other than runoff.

Some researchers have improved the modeling of hydrological processes by replacing or improving the hydrological processes systematically in climate models. These efforts can 
enhance the stability of the system compared to modifying a scheme separately. For example, Chen et al. (2011a, 2011b) developed the regional atmosphere-hydrology model RegHCMTE (Regional Hydroclimate Model for the Tigris-Euphrates) based on the atmospheric model MM5 (a fifth-generation mesoscale model), a hydrological model and a snowmelt model. The results showed that RegHCM-TE can simulate regional precipitation and annual runoff well. Sheng et al. (2017) altered the runoff and river routing schemes in CLM 4.0 using the geomorphology-based hydrological model to improve runoff simulation. In addition, some studies have incorporated groundwater models into land surface models to investigate changes in groundwater (Kollet and Maxwell, 2008a; Maxwell and Miller, 2005) and base flow (Kollet and Maxwell, 2008b). However, with the continuous improvement in the description of hydrological processes in land surface models, large-scale hydrological parameterization schemes for climate simulation are emerging, and studies using algorithms in hydrological models to replace parameterization schemes in climate models are gradually decreasing (Niu et al., 2005; Vrettas and Fung, 2015).

\subsection{Development of large-scale hydrological models}

To estimate global and regional water resources more accurately, large-scale hydrological models based on watershed hydrological model frameworks have been developed in the past decade (Bierkens, 2015; Sood and Smakhtin, 2015) and have become one of the most important branches of climate change research (Yong et al., 2006). Based on distributed hydrological models, researchers have extended hydrological simulation from the watershed scale to the continental scale or global scale by improving the grid scale (Liu et al., 2003; Notter et al., 2007). Large-scale hydrological models are mostly based on conceptual or semi-distributed models and are primarily used to simulate runoff processes in large watersheds and to assess the impacts of climate change on hydrological situations. Table 2 lists some commonly used large-scale hydrological models, including MACRO-PDM (Arnell, 1999) and PCR-GLOBWB (Bergstrom and Graham, 1998; van Beek et al., 2011). These models simulate runoff based on the outputs of climate models, which allows the effects of climate change on water resources to be assessed in large-scale basins. However, these models are usually applied to the simulation of rainfall-runoff and the calculation of water budgets; they do not consider energy balance and cannot fully describe the water and energy exchange processes of land-atmosphere interfaces ( $\mathrm{Su}$ and Hao, 2001).

In recent years, the parameterization schemes of large-scale hydrological models have been improved by incorporating energy processes, ecological processes, human activities and land use change processes. The improved models include the VIC model (Liang et al., 1994), the integrated model for global water resource assessment (Hanasaki et al., 2008) and the Integrated Hydrological Modeling System (IHMS) (Ragab and Bromley, 2010). While the improved parameterization schemes of these large-scale hydrological models reduce the gaps between the land surface models, the models still focus on the simulation of hydrological processes, and they still have some deficiencies in the simulation of biochemical processes. These drawbacks make it difficult for these models to replace land surface models in a short term. In addition, large-scale hydrological models lose some of their advantages as the scale increases to the watershed scale, and these models are mostly used for the simulation of monthly and inter-annual runoff. For watershed-scale flood simulations, researchers 
Table 2 Comparison of parameterization schemes of some global hydrological models (Haddeland et al., 2011)

\begin{tabular}{|c|c|c|c|c|c|c|c|}
\hline Model & $\begin{array}{c}\text { Forcing } \\
\text { variables }\end{array}$ & $\begin{array}{l}\text { Energy } \\
\text { balance }\end{array}$ & ET scheme & Runoff scheme & Snow scheme & $\begin{array}{l}\text { Vegetation } \\
\text { dynamics }\end{array}$ & $\begin{array}{c}\mathrm{CO}_{2} \\
\text { affected }\end{array}$ \\
\hline $\mathrm{DBH}$ & $\begin{array}{l}\text { P, T, W, Q, LW, } \\
\text { SW, SP }\end{array}$ & Yes & Energy balance & $\begin{array}{l}\text { Infiltration } \\
\text { excess }\end{array}$ & $\begin{array}{l}\text { Energy bal- } \\
\text { ance }\end{array}$ & No & Constant \\
\hline $\mathrm{H} 08$ & $\begin{array}{l}\mathrm{R}, \mathrm{S}, \mathrm{T}, \mathrm{W}, \mathrm{Q}, \\
\mathrm{LW}, \mathrm{SW}, \mathrm{SP}\end{array}$ & Yes & Bulk formula & $\begin{array}{l}\text { Saturation } \\
\text { excess }\end{array}$ & $\begin{array}{l}\text { Energy bal- } \\
\text { ance }\end{array}$ & No & No \\
\hline Plum & $\mathrm{P}, \mathrm{T}, \mathrm{La}_{\mathrm{wn}}, \mathrm{SW}$ & No & Priestley-Taylor & $\begin{array}{l}\text { Saturation } \\
\text { excess }\end{array}$ & Degree-day & Yes & Yes \\
\hline Mac-PDM.09 & $\begin{array}{l}\mathrm{P}, \mathrm{T}, \mathrm{W}, \mathrm{Q}, \mathrm{La}_{\mathrm{wn}}, \\
\mathrm{SW}\end{array}$ & No & Penman-Montecito & $\begin{array}{l}\text { Saturation ex- } \\
\text { cess }\end{array}$ & Degree-day & No & No \\
\hline MATSIRO & $\begin{array}{l}\mathrm{R}, \mathrm{S}, \mathrm{T}, \mathrm{W}, \mathrm{Q}, \\
\mathrm{LW}, \mathrm{SW}, \mathrm{SP}\end{array}$ & Yes & Bulk formula & $\begin{array}{l}\text { Infiltration and } \\
\text { saturation ex- } \\
\text { cess }\end{array}$ & $\begin{array}{l}\text { Energy bal- } \\
\text { ance }\end{array}$ & No & Constant \\
\hline MPI-HM & $\begin{array}{l}\mathrm{P}, \mathrm{T}, \mathrm{W}, \mathrm{Q}, \mathrm{La}_{\mathrm{wn}}, \\
\mathrm{SW}, \mathrm{SP}\end{array}$ & No & Penman-Montecito & $\begin{array}{l}\text { Saturation ex- } \\
\text { cess }\end{array}$ & Degree-day & No & No \\
\hline PCR-GLOBWB & $\mathrm{P}, \mathrm{T}$ & No & Harmon & $\begin{array}{l}\text { Saturation ex- } \\
\text { cess }\end{array}$ & Degree-day & No & No \\
\hline Water GAP & $\mathrm{P}, \mathrm{T}, \mathrm{La}_{\mathrm{wn}}, \mathrm{SW}$ & No & Priestley-Taylor & Beta function & Degree-day & No & No \\
\hline WBM & $\mathrm{P}, \mathrm{T}$ & No & Harmon & Beta function & $\begin{array}{l}\text { Empirical } \\
\text { formula }\end{array}$ & No & No \\
\hline
\end{tabular}

$\mathrm{R}$ : rainfall rate, $\mathrm{S}$ : snowfall rate, $\mathrm{P}$ : precipitation rate (rain and snow calculated in the model), T: air temperature, W: wind speed, Q: air specific humidity, LW: down welling long wave radiation; $\mathrm{La}_{\mathrm{wn}}$ : net long wave radiation; SW: down welling shortwave radiation, SP: surface pressure

still use watershed hydrological models as their main tools. Therefore, to achieve the feedback between hydrological process and atmospheric process, future work should address following questions, such as how to improve the accuracy of hydrological process simulation climate model, how to optimize the coupling method.

\section{Development of atmosphere-hydrology simulations from one-way cou- pled to fully coupled}

Since the 1990s, research has focused on coupled models in the fields of atmosphere and hydrology. The simulation ability of climate models at the watershed scale has been expanded by combining the advantages of climate and hydrological models (Yu et al., 2006; Kavvas et al., 2013). Due to the importance of flood simulation and research on the impacts of climate change on water resources, coupled atmosphere-hydrology simulations have become a new topic in the IPCC technical report (IPCC, 2015).

Most studies on coupled atmosphere-hydrology models have focused on the influence of climate change on the hydrological process within a river basin, mostly using one-way coupling. The outputs of climate models (e.g. precipitation, temperature and other meteorological factors) after downscaling drive hydrological models to simulate the hydrological variables such as evapotranspiration and runoff. This one-way coupling method is easy to operate and has been widely used (Wilby and Wigley, 2000; Kruk et al., 2013; Xu et al., 2015). However, one-way coupling does not result in good simulation accuracy for hydrological processes within a certain basin because it lacks the feedback of hydrology with atmosphere. As a result, atmosphere-hydrology simulation has changed from one-way coupled simula- 
tion to fully coupled simulation. In studies on fully coupled simulation, some researchers have incorporated algorithms of runoff, infiltration and evaporation into land surface models to improve the simulation of hydrological processes.

The accuracy of runoff simulations can be improved by replacing or improving the hydrological process in the land surface model. However, this embedded coupling method is still based on the land surface model and thus cannot take advantage of the superior watershed-scale precision of hydrological models. To combine the advantages of climate and hydrological models, some researchers have fully coupled climate and hydrological models. In their methods climate models and hydrological models could be coordinated to compile and maintain their respective independence. In the coupling process, the hydrological model and the climate model exchange variables using scale conversion methods, and the hydrological model is driven by the outputs of the climate model. Hydrological variables such as evaporation and runoff are then fed to the land surface model through up-scaling methods. This method can preserve the advantages of both the climate and hydrological models and is a main development direction of future atmosphere-hydrology simulations (Peng et al., 2014; Yu and Cao, 2008).

At present, many issues remain to be solved in atmosphere-hydrology simulations. Even so, substantial research progress has been made. For example, Larsen et al. (2014) developed a fully coupled atmosphere-hydrology model for a Danish catchment by coupling the climate model HIRHAM with the hydrological model MIKE SHE. To exchange data between HIRHAM and MIKE SHE, the authors modified the MIKE SHE model using parallel algorithms to ensure the cooperative operation of HIRHAM and MIKE SHE under Linux and Windows platforms. The MIKE SHE model is driven by a bilinear interpolation of the outputs of the HIRHAM model, including surface wind speed, temperature, humidity and precipitation. The latent and sensible heat fluxes provided by MIKE SHE are fed to the atmosphere through the land surface model of the HIRHAM model. The coupled model, which keeps the advantages of both HIRHAM and MIKE SHE, can be used to simulate watershed-scale runoff using MIKE SHE along with regional climate using HIRHAM. Senatore et al. (2015) coupled the regional climate model WRF with the WRF-Hydro model to construct a fully coupled atmosphere-hydrology model and applied the model in the central Mediterranean. Wagner et al. (2016) coupled the regional climate model WRF with the distributed hydrological model HMS to develop a fully coupled mesoscale atmosphere-hydrology model. They applied the model in the Poyang Lake basin of China. Kerandi et al. (2018) used the fully coupled WRF-Hydro modeling system to investigate joint atmospheric-terrestrial water balances.

In addition, Maxwell et al. (2011) and Shrestha et al. (2014) fully coupled a climate model with a three-dimensional groundwater model to improve the runoff simulation, soil moisture and other variables in the climate model. These works retained the land surface hydrological process of the climatic model and can simulate three-dimensional groundwater movement.

\section{Challenges and opportunities for future research}

After years of development, the one-way coupling method of atmosphere-hydrology has been widely applied. However, fully coupled atmosphere-hydrology requires further re- 
search to improve model matching and adaptability, uncertainty assessment and so on. The focus of future development includes the following aspects.

\subsection{Model matching and adaptability}

The different operating platforms of hydrological models and climate models increase the difficulty associated with coupled atmosphere-hydrology simulations. Hydrological models use Windows graphical interfaces, whereas climate models adopt the parallel algorithm of the Linux system. The differences between the operating platforms make the data exchange between the hydrological and climate models more difficult. Larsen et al. (2014) made great efforts to overcome this difficulty by recompiling the hydrological model and a new coupler. Gregersen et al. (2007) developed the cross-platform coupler Open to allow data exchange between Windows and Linux platforms, providing a software approach for atmosphere-hydrology coupling. Another way to couple climate models with hydrological models is to port the hydrological model and realize its compiling under a Linux system; however, the software required for this method is difficult to realize.

In addition to the different operating platforms, modifying the hydrological process in a land surface model may cause some issues during coupling. Although the stability of the fully coupled method is much better than that of modifying a certain scheme, the water balance in the land surface model affects the energy balance, vegetation growth and other factors, which may cause the mismatch of the model system (Fiorentini et al., 2015; van Dijk et al., 2015). Therefore, in a two-way coupling study, it is necessary to evaluate the secondary changes caused by updating the water balance in the model.

\subsection{Grid conversion methods among scales}

Due to the mismatched resolution between the climate model and the hydrological model, the outputs of the climate models need to be downscaled, while the results of the hydrological model related to the evaporation and runoff need to upscale to match the climate model. Therefore, methods for scale transformation are a research hotspot. As different interpolation methods have their own scopes and limitations, there is no one best interpolation method (Chiew et al., 2010; Landman et al., 2009). Therefore, how to divide the grid (Bierkens et al., 2015), select the most effective scale transformation method or develop a more extensive algorithm, and reduce the deviation in simulation results caused by the heterogeneity of the grid are some of the major issues in future studies of atmosphere-hydrology coupling.

\subsection{Improvement of model parameters and their uncertainty}

Optimizing the physical parameterization schemes and improving the simulation precision are fundamental areas of research in atmosphere-hydrology coupling. Although considerable progress has been made in hydrological models and climate models, more attention should be given to improving the physical parameterization schemes related to the water cycle (Costa et al., 2003; Foley et al., 2005). For example, land cover and land use are relatively fixed in climate models; most models fail to consider the dynamic process of land cover/use change. At present, a few models (such as the CLM) introduce the process of dynamic vegetation growth (Lawrence and Chase, 2010). In addition to land cover/use changes, human exploitation, utilization and deployment of water resources have affected the water cy- 
cle. The interaction between human activities and global climate-hydrological processes has become a frontier issue in water resources-related research. How to parameterize the impact of human activities on water resources is a direction of land surface models and hydrological models in the future (Barnett et al., 2008; Wang et al., 2006). Improving the parameterization of vegetation biochemical processes along with frozen soil, cities, lakes and other types of underlying surfaces is also important (Luo et al., 2009; Subin et al., 2012).

Moreover, many empirical parameters in the parameterization schemes of climate models and hydrological models are uncertain in the process of real-time transfer and coupling, affecting the simulation (Benke et al., 2008; Salamon and Feyen, 2009). Quantifying the uncertainties caused by the parameters and developing methods for parameter optimization and data assimilation should help reduce the uncertainty in the parameters (Liu et al., 2012).

\subsection{Parameter transfer and regional applicability}

The parameter transferring approach remains difficult in hydrology, and the regional applicability of atmosphere-hydrology coupling is a key issue to be addressed. Hydrological models use statistical algorithms to describe the relationships among hydrological elements, and the simulation accuracy depends on the calibration of the model parameters. For different study basins, the hydrological model requires observation data to calibrate the parameters. Therefore, coupled atmosphere-hydrology models are usually developed for a specific watershed, and applying the models in different areas requires substantial parameter calibration and validation. Thus, applicability of coupled models on the regional scale is lacking.

Many researchers have proposed and compared numerous methods of parameter transfer to improve the applicability of hydrological models. However, the developed methods are similar to the downscaling method, and there is still no best method (Heuvelmans et al., 2004; Patil and Stieglitz, 2015). Oubeidillah et al. (2014) established a parameter dataset for the VIC model in the United States, which has made a positive contribution to the study of water resources and climate change. However, for other small-scale hydrological models, continental- or national-scale parameter datasets have not been established.

\subsection{The challenge of hyper-resolution simulation}

To address global or regional water cycle-related issues and application requirements more accurately under global change, developing coupled atmosphere-hydrology models with high or hyper-resolution (less than $1 \mathrm{~km}$ ) will be a key direction for future research (Wood et al., 2011; Beven et al., 2015; Bierkens et al., 2015). The construction of land surface and hydrological models with hyper-resolution not only requires the support of supercomputers to enhance the resolution and computational capability of the model, it also faces the challenges of the mechanism of hydrological-climate interaction in the higher spatial resolution (Beven and Cloke, 2012). Therefore, how to parameterize the interaction between surface water and groundwater under the condition of vegetation and topography with the higher spatial resolution, the mechanism of terrestrial-atmosphere interaction and the spatio-temporal distribution of soil moisture and evapotranspiration under the corresponding scales are the scientific basis for the development of the hyper-resolution model. A few scholars are conducting research in this area. Singh et al. (2015) investigated the impacts of 1-km-resolution land use and soil on CLM simulation. They compared the changes in factors 
and processes such as runoff and infiltration compared to $100-\mathrm{m}$ resolution. The results showed that the hyper-resolution description of the hydrological process greatly affected the simulation. At the same time, establishing a global observational network and a dataset of remote sensing will be an important task for the study of atmosphere-hydrology coupling with hyper-resolution.

\section{Summary and concluding remarks}

Due to lack of consideration of hydrological processes under different underlying surfaces in climate models, runoff simulations of climate models at a watershed scale is less accurate. Therefore, two-way atmosphere-hydrology coupling, which keeps the advantages of both hydrological and climate models, has become a key focus of climate change and water resources research.

The basis of two-way coupling is improving the hydrological process of the land surface model with the hydrological model. Conventionally, the climate model provides climate-forced input to the hydrological model through one-way coupling; however, this method lacks climate feedback from the hydrological model and will be replaced by the fully coupled method. The fully coupled method simulates hydrological processes at the watershed scale based on real-time feedback between the hydrological and climate models. The water cycle balance in the climate model is then modified accordingly.

At present, research on fully coupled atmosphere-hydrology models is not mature. Although a few works have achieved cross-platform cooperative operation between the hydrological model and the climate model, many studies need to be done, such as improving the potential mismatch in hydrological models and climate models, different scale conversion, improvement of physical process scheme of sub-grid, parameter uncertainty, parameter transfer method, region applicability and high-resolution simulation. Future research will focus on how to solve the above difficulties and improve the stability, applicability and accuracy of fully coupled models.

In view of the problems related to fully coupled atmosphere-hydrology simulation, future research will focus on atmospheric-hydrological modeling and transformation at different spatio-temporal scales; the parameterization of dynamic land cover/use change, human activities and other factors such as evapotranspiration, soil moisture, surface and groundwater under different underlying surfaces; the reduction in the mismatch and uncertainty of the model coupling process; the optimization of model parameters and parameter transfer methods for ungauged basins; and the exploration of the mechanism of atmosphere-hydrology coupling with high/hyper-resolution.

\section{References}

Arnell N W, 1999. A simple water balance model for the simulation of streamflow over a large geographic domain. Journal of Hydrology, 217(3/4): 314-335.

Barnett T P, Pierce D W, Hidalgo H G et al., 2008. Human-induced changes in the hydrology of the western United States. Science, 319(5866): 1080-1083.

Bates B, Kundzewicz Z, Wu S, 2008. Climate change and water. Intergovernmental Panel on Climate Change Secretariat, Geneva.

Benke K K, Lowell K E, Hamilton A J, 2008. Parameter uncertainty, sensitivity analysis and prediction error in a 
water-balance hydrological model. Mathematical and Computer Modelling, 47(11/12): 1134-1149.

Bergstrom S, Graham L P, 1998. On the scale problem in hydrological modelling. Journal of Hydrology, 211(1-4): 253-265.

Beven K, Cloke H, Pappenberger F et al., 2015. Hyperresolution information and hyperresolution ignorance in modelling the hydrology of the land surface. Science China-Earth Sciences, 58(1): 25-35.

Beven K J, Cloke H L, 2012. Comment on "Hyperresolution global land surface modeling: Meeting a grand challenge for monitoring Earth's terrestrial water” by Eric F. Wood et al. Water Resources Research, 48(1): W01801.

Bierkens M F P, 2015. Global hydrology 2015: State, trends, and directions. Water Resources Research, 51(7): 4923-4947.

Bierkens M F P, Bell V A, Burek P et al., 2015. Hyper-resolution global hydrological modelling: What is next? "Everywhere and locally relevant". Hydrological Processes, 29(2): 310-320.

Chen F, Xie Z H, 2010. Effects of interbasin water transfer on regional climate: A case study of the Middle Route of the South-to-North Water Transfer Project in China. Journal of Geophysical Research: Atmospheres, 115(D11): 112 .

Chen Z Q R, Kavvas M L, Ohara N et al., 2011a. Coupled regional hydroclimate model and its application to the Tigris-Euphrates Basin. Journal of Hydrologic Engineering, 16(12): 1059-1070.

Chen Z Q R, Kavvas M L, Ohara N et al., 2011b. Impact of water resources utilization on the hydrology of mesopotamian marshlands. Journal of Hydrologic Engineering, 16(12): 1083-1092.

Chiew F H S, Kirono D G C, Kent D M et al., 2010. Comparison of runoff modelled using rainfall from different downscaling methods for historical and future climates. Journal of Hydrology, 387(1/2): 10-23.

Costa M H, Botta A, Cardille J A, 2003. Effects of large-scale changes in land cover on the discharge of the Tocantins River, Southeastern Amazonia. Journal of Hydrology, 283(1-4): 206-217.

Dai Y J, Zeng X B, Dickinson R E et al., 2003. The common land model. Bulletin of the American Meteorological Society, 84(8): 1013-1023.

Decker M, Zeng X B, 2009. Impact of modified richards equation on global soil moisture simulation in the Community Land Model (CLM3.5). Journal of Advances in Modeling Earth Systems, 1(3): 22.

Fiorentini M, Orlandini S, Paniconi C, 2015. Control of coupling mass balance error in a process-based numerical model of surface-subsurface flow interaction. Water Resources Research, 51(7): 5698-5716.

Foley J A, DeFries R, Asner G P et al., 2005. Global consequences of land use. Science, 309(5734): 570-574.

Gregersen J B, Gijsbers P J A, Westen S J P, 2007. OpenMI: Open modelling interface. Journal of Hydroinformatics, 9(3): 175-191.

Guo S, Liu C, 1997. Large scale hydrological models and its coupling with atmospheric models. Journal of Hydraulic Engineering, 7: 37-41. (in Chinese)

Habets F, Noilhan J, Golaz C et al., 1999. The ISBA surface scheme in a macroscale hydrological model applied to the Hapex-Mobilhy area (Part II): Simulation of streamflows and annual water budget. Journal of Hydrology, 217(1/2): 97-118.

Haddeland I, Clark D B, Franssen W et al., 2011. Multimodel estimate of the global terrestrial water balance: Setup and first results. Journal of Hydrometeorology, 12(5): 869-884.

Haddeland I, Skaugen T, Lettenmaier D P, 2006. Anthropogenic impacts on continental surface water fluxes. Geophysical Research Letters, 33(8): L08406.

Hanasaki N, Kanae S, Oki T et al., 2008. An integrated model for the assessment of global water resources (Part 1): Model description and input meteorological forcing. Hydrology and Earth System Sciences, 12(4): 1007-1025.

Heuvelmans G, Muys B, Feyen J, 2004. Evaluation of hydrological model parameter transferability for simulating the impact of land use on catchment hydrology. Physics and Chemistry of the Earth, 29(11/12): 739-747.

IPCC, 2015. Climate Change 2014: Mitigation of Climate Change. Vol. 3. Cambridge: Cambridge University Press.

Kavvas M L, Kure S, Chen Z Q et al., 2013. WEHY-HCM for modeling interactive atmospheric-hydrologic processes at watershed scale. I: Model description. Journal of Hydrologic Engineering, 18(10): 1262-1271.

Kerandi N, Arnault J, Laux P et al., 2018. Joint atmospheric-terrestrial water balances for East Africa: A WRF-Hydro case study for the upper Tana River basin. Theoretical and Applied Climatology, 131(3): 1337-1355.

Kollet S J, Maxwell R M, 2008a. Capturing the influence of groundwater dynamics on land surface processes using an integrated, distributed watershed model. Water Resources Research, 44(2): W02402.

Kollet S J, Maxwell R M, 2008b. Demonstrating fractal scaling of baseflow residence time distributions using a fully-coupled groundwater and land surface model. Geophysical Research Letters, 35(7): L07402.

Kruk N S, Vendrame I F, Chou S C, 2013. Coupling a mesoscale atmospheric model with a distributed hydrologi- 
cal model applied to a watershed in Southeast Brazil. Journal of Hydrologic Engineering, 18(1): 58-65.

Landman W A, Kgatuke M J, Mbedzi M et al., 2009. Performance comparison of some dynamical and empirical downscaling methods for South Africa from a seasonal climate modelling perspective. International Journal of Climatology, 29(11): 1535-1549.

Larsen M A D, Refsgaard J C, Drews M et al., 2014. Results from a full coupling of the HIRHAM regional climate model and the MIKE SHE hydrological model for a Danish catchment. Hydrology and Earth System Sciences, 18(11): 4733-4749.

Lawrence P J, Chase T N, 2010. Investigating the climate impacts of global land cover change in the community climate system model. International Journal of Climatology, 30(13): 2066-2087.

Li M X, Ma Z G, Lv M X, 2017. Variability of modeled runoff over China and its links to climate change. Climatic Change, 144(3): 433-445.

Liang X, Lettenmaier D P, Wood E F et al., 1994. A simple hydrologically based model of land-surface water and energy fluxes for general-circulation models. Journal of Geophysical Research-Atmospheres, 99(D7): $14415-14428$.

Liang X, Wood E F, Lettenmaier D P et al., 1998. The Project for Intercomparison of Land-surface Parameterization Schemes (PILPS) phase 2(c) Red-Arkansas River basin experiment: 2. Spatial and temporal analysis of energy fluxes. Global and Planetary Change, 19(1-4): 137-159.

Liu C, Li D, Tian Y et al., 2003. An application study of dem based distributed hydrological model on macroscale watershed. Progress in Geography, 22(5): 437-445. (in Chinese)

Liu Y, Weerts A H, Clark M et al., 2012. Advancing data assimilation in operational hydrologic forecasting: Progresses, challenges, and emerging opportunities. Hydrology and Earth System Sciences, 16(10): 3863-3887.

Livneh B, Xia Y L, Mitchell K E et al., 2010. Noah LSM snow model diagnostics and enhancements. Journal of Hydrometeorology, 11(3): 721-738.

Luo S Q, Lu S H, Zhang Y, 2009. Development and validation of the frozen soil parameterization scheme in Common Land Model. Cold Regions Science and Technology, 55(1): 130-140.

Manabe S, 1969. Climate and the ocean circulation: I. The atmospheric circulation and the hydrology of the earth's surface. Monthly Weather Review, 97(11): 739-774.

Maxwell R M, Lundquist J K, Mirocha J D et al., 2011. Development of a coupled groundwater-atmosphere model. Monthly Weather Review, 139(1): 96-116.

Maxwell R M, Miller N L, 2005. Development of a coupled land surface and groundwater model. Journal of Hydrometeorology, 6(3): 233-247.

Ning L K, Xia J, Zhan C S et al., 2016. Runoff of arid and semi-arid regions simulated and projected by CLM-DTVGM and its multi-scale fluctuations as revealed by EEMD analysis. Journal of Arid Land, 8(4): $506-520$.

Niu G Y, Yang Z L, Dickinson R E et al., 2005. A simple TOPMODEL-based runoff parameterization (SIMTOP) for use in global climate models. Journal of Geophysical Research-Atmospheres, 110(D21): D21106.

Notter B, MacMillan L, Viviroli D et al., 2007. Impacts of environmental change on water resources in the Mt. Kenya region. Journal of Hydrology, 343(3/4): 266-278.

Oleson K W, Lawrence D M, Gordon B et al., 2010. Technical description of version 4.0 of the Community Land Model (CLM).

Oubeidillah A A, Kao S C, Ashfaq M et al., 2014. A large-scale, high-resolution hydrological model parameter data set for climate change impact assessment for the conterminous US. Hydrology and Earth System Sciences, 18(1): 67-84.

Patil S D, Stieglitz M, 2015. Comparing Spatial and temporal transferability of hydrological model parameters. Journal of Hydrology, 525: 409-417.

Peng T, Shen T, Gao Y et al., 2014. Research and application progress on basin hydro-meteorology coupling flood forecasting. Advances in Meteorological Science and Technology, 2(4): 52-58. (in Chinese)

Pokhrel Y, Hanasaki N, Koirala S et al., 2012. Incorporating anthropogenic water regulation modules into a land surface model. Journal of Hydrometeorology, 13(1): 255-269.

Ragab R, Bromley J, 2010. IHMS-integrated hydrological modelling system. Part 1. Hydrological processes and general structure. Hydrological Processes, 24(19): 2663-2680.

Sahoo A K, Dirmeyer P A, Houser P R et al., 2008. A study of land surface processes using land surface models over the Little River Experimental Watershed, Georgia. Journal of Geophysical Research: Atmospheres, 113(D20): D20121.

Salamon P, Feyen L, 2009. Assessing parameter, precipitation, and predictive uncertainty in a distributed hydro- 
logical model using sequential data assimilation with the particle filter. Journal of Hydrology, 376(3/4): 428-442.

Senatore A, Mendicino G, Gochis D J et al., 2015. Fully coupled atmosphere-hydrology simulations for the central Mediterranean: Impact of enhanced hydrological parameterization for short and long time scales. Journal of Advances in Modeling Earth Systems, 7(4): 1693-1715.

Seuffert G, Gross P, Simmer C et al., 2002. The influence of hydrologic modeling on the predicted local weather: Two-way coupling of a mesoscale weather prediction model and a land surface hydrologic model. Journal of Hydrometeorology, 3(5): 505-523.

Sheng M, Lei H, Jiao Y et al., 2017. Evaluation of the runoff and river routing schemes in the community land model of the Yellow River Basin. Journal of Advances in Modeling Earth Systems, 9(8): 2993-3018.

Shrestha P, Sulis M, Masbou M et al., 2014. A scale-consistent terrestrial systems modeling platform based on COSMO, CLM, and ParFlow. Monthly Weather Review, 142(9): 3466-3483.

Singh R S, Reager J T, Miller N L et al., 2015. Toward hyper-resolution land-surface modeling: The effects of fine-scale topography and soil texture on CLM4.0 simulations over the southwestern US. Water Resources Research, 51(4): 2648-2667.

Sood A, Smakhtin V, 2015. Global hydrological models: A review. Hydrological Sciences Journal-Journal Des Sciences Hydrologiques, 60(4): 549-565.

Su F, Hao Z, 2001. Review of land-surface hydrological processes parameterization. Advance in Earth Sciences, 16(6): 795-801. (in Chinese)

Subin Z M, Riley W J, Mironov D, 2012. An improved lake model for climate simulations: Model structure, evaluation, and sensitivity analyses in CESM1. Journal of Advances in Modeling Earth Systems, 4(1): M02001.

van Beek L P H, Wada Y, Bierkens M F P, 2011. Global monthly water stress: 1. Water balance and water availability. Water Resources Research, 47(7): W07517.

van Dijk A I J M, Gash J H, van Gorsel E et al., 2015. Rainfall interception and the coupled surface water and energy balance. Agricultural and Forest Meteorology, 214/215: 402-415.

Vrettas M D, Fung I Y, 2015. Toward a new parameterization of hydraulic conductivity in climate models: Simulation of rapid groundwater fluctuations in Northern California. Journal of Advances in Modeling Earth Systems, 7(4): 2105-2135.

Wagner S, Fersch B, Yuan F et al., 2016. Fully coupled atmospheric-hydrological modeling at regional and long-term scales: Development, application, and analysis of WRF-HMS. Water Resources Research, 52(4): 3187-3211.

Wang C, Wang Y Y, Wang P F, 2006. Water Quality Modeling and Pollution Control for the Eastern Route of South to North Water Transfer Project in China. Journal of Hydrodynamics, 18(3): 253-261.

Wilby R L, Wigley T M L, 2000. Precipitation predictors for downscaling: Observed and general circulation model relationships. International Journal of Climatology, 20(6): 641-661.

Wood E F, Roundy J K, Troy T J et al., 2011. Hyperresolution global land surface modeling: Meeting a grand challenge for monitoring Earth's terrestrial water. Water Resources Research, 47(5): W05301.

$\mathrm{Xu}$ Y, Gao X, Zhu Q et al., 2015. Coupling a regional climate model and a distributed hydrological model to assess future water resources in Jinhua River Basin, East China. Journal of Hydrologic Engineering, 20(4): 04014054.

Yang C, Lin Z, Hao Z et al., 2007. Revview of coupling atmospheric and hydrologic models. Advances in Earth Science, 22(8): 810-817. (in Chinese)

Yong B, Ren L, Chen X et al., 2009. Development of a large-scale hydrological model TOPX and its coupling with regional integrated environment modeling system RIEMS. Chinese Journal of Geophysics, 52(8): 1954-1965. (in Chinese)

Yong B, Zhang W, Liu C, 2006. Advances in the coupling study of hydrological models and land-surface models. Journal of Glaciology and Geocryology, 28(6): 961-970. (in Chinese)

Yu F, Cao Y, 2008. Research progress summarization of the impacts of global climate change to the regional water resources. Journal of Water Resources and Water Engineering, 19(4): 92-97. (in Chinese)

Yu Z B, Pollard D, Cheng L, 2006. On continental-scale hydrologic simulations with a coupled hydrologic model. Journal of Hydrology, 331(1/2): 110-124.

Zeng X M, Zhao M, Su B K et al., 2003. Simulations of a hydrological model as coupled to a regional climate model. Advances in Atmospheric Sciences, 20(2): 227-236.

Zou J, Xie Z H, Yu Y et al., 2014. Climatic responses to anthropogenic groundwater exploitation: A case study of the Haihe River Basin, Northern China. Climate Dynamics, 42(7/8): 2125-2145. 